
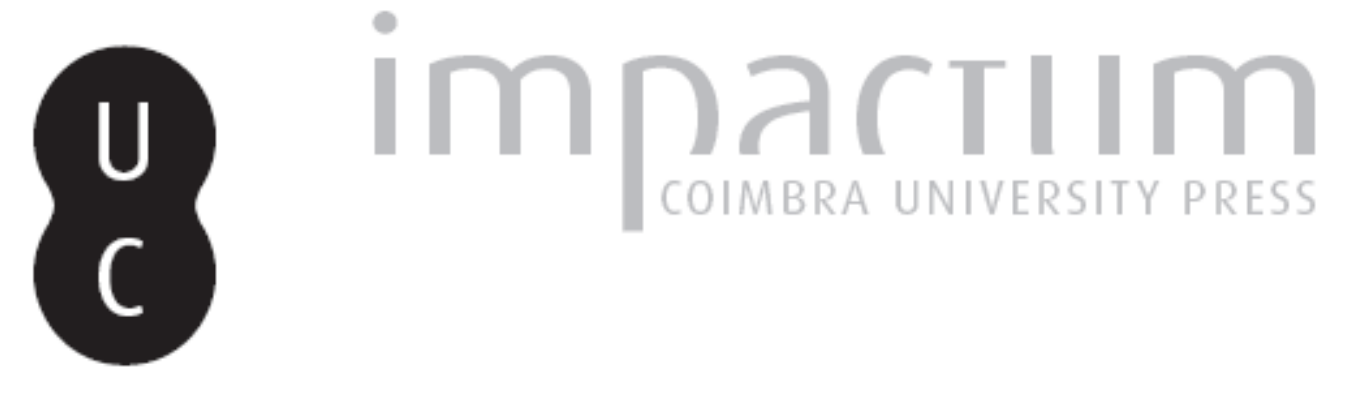

\title{
Novalis e Pessoa: lucidez poética e reflexão onírica
}

Autor(es): $\quad$ Souza, Cláudia; Suzuki, Márcio

Publicado por: Faculdade de Letras da Universidade de Coimbra, Instituto de Estudos

URL

persistente:

URI:http://hdl.handle.net/10316.2/37871

DOI:

DOI:http://dx.doi.org/10.14195/0872-0851_47_1

Accessed : $\quad$ 26-Apr-2023 13:52:31

A navegação consulta e descarregamento dos títulos inseridos nas Bibliotecas Digitais UC Digitalis, UC Pombalina e UC Impactum, pressupõem a aceitação plena e sem reservas dos Termos e Condições de Uso destas Bibliotecas Digitais, disponíveis em https://digitalis.uc.pt/pt-pt/termos.

Conforme exposto nos referidos Termos e Condições de Uso, o descarregamento de títulos de acesso restrito requer uma licença válida de autorização devendo o utilizador aceder ao(s) documento(s) a partir de um endereço de IP da instituição detentora da supramencionada licença.

Ao utilizador é apenas permitido o descarregamento para uso pessoal, pelo que o emprego do(s) título(s) descarregado(s) para outro fim, designadamente comercial, carece de autorização do respetivo autor ou editor da obra.

Na medida em que todas as obras da UC Digitalis se encontram protegidas pelo Código do Direito de Autor e Direitos Conexos e demais legislação aplicável, toda a cópia, parcial ou total, deste documento, nos casos em que é legalmente admitida, deverá conter ou fazer-se acompanhar por este aviso.

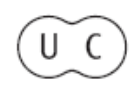




\section{REVISTA FILOSÓFICA COIMBRA}

vol. 24 - número 47- março 2015

vol. 24 - número 47- março 2015

Fundação Eng. António de Almeida

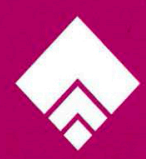




\title{
NOVALIS E PESSOA: LUCIDEZ POÉTICA E REFLEXÃO ONÍRICA
}

\author{
CLÁUdIA SOUZA ${ }^{1}$ \\ MÁRCIO SUZUKI ${ }^{2}$
}

\begin{abstract}
Resumo: O texto que segue é uma tentativa de aproximar Fernando Pessoa e Novalis, comparando suas concepções filosóficas e poéticas. Estuda-se como se relacionam vigília e sonho, consciência e ironia nas obras dos dois autores, partindo de um poema de Álvaro de Campos, de textos do espólio pessoano e dos fragmentos novalisianos.
\end{abstract}

Palavras-chave: Fernando Pessoa, Novalis, filosofia, poesia.

Abstract: This article attemps to approximate Fernando Pessoa to Novalis, comparing their philosophical and poetic conceptions. It will be studied how wake and dream, consciousness and irony are connected in the works of both authors. To this goal we analyze a poem by Álvaro de Campos and unpublished texts from Fernando Pessoa, which show how the Portuguese poet read Novalis' fragments.

Keywords: Fernando Pessoa, Novalis, philosophy, poetry.

De modo nem sempre direto, mas significativo, a filosofia alemã marcou presença no pensamento de Fernando Pessoa. O engenheiro metafísico Álvaro de Campos menciona, por exemplo, em pelo menos dois momentos de sua obra poética a filosofia do Idealismo Alemão. Em Tabacaria, seu poema mais conhecido, compara sua inquietação interior ao trabalho intelectual do autor da Crítica da razão pura ("Tenho feito mais filosofias em segredo que

1 Pós-doutoranda do Departamento de Filosofia da Universidade de São Paulo, com pesquisa financiada pela Fapesp. E-mail: claudiasouzzza@hotmail.com

2 Professor do Departamento de Filosofia da Universidade de São Paulo e bolsista do CNPq. E-mail: marciosuzuki@usp.br 
nenhum Kant escreveu"), e um outro poema também assinado por Campos o eu lírico põe na boca de um suposto interlocutor a frase intrigante, com a qual, entretanto, ele afirma concordar "em absoluto":

...Dizias

Que no desenvolvimento da metaphysica

De Kant a Hegel

Alguma coisa se perdeu ${ }^{3}$.

A sentença, que ocupa o centro do poema, dá o que pensar. Tanto mais que os versos restantes silenciarão o que se perdeu no desenvolvimento da metafísica na Alemanha. O aguçamento da curiosidade é inevitável: que seria aquela alguma coisa indefinida que levou sumiço no breve período que separa os sistemas de Kant e Hegel?

Com o cuidado de não assimilar imediatamente Fernando Pessoa a Álvaro de Campos, nem este ao eu lírico, um mergulho mais profundo na análise do poema pode talvez conduzir o leitor à descoberta de um laço de afinidade mais estreito entre o poeta português e o pensamento idealista alemão: a pista para se chegar a ele estaria já no verso de abertura, embora tampouco este apresente relação imediata evidente com o tema.

"Gostava de gostar de gostar": a oração mais parece uma afirmação redundante, dada a enunciação, por três vezes, do mesmo verbo, duas delas na forma do infinitivo impessoal e uma terceira na primeira pessoa do pretérito imperfeito. Lembrando uma cantiga, este verso inicial apresenta uma construção simples e fechada (com a dupla regência em "de" terminando com o ponto final), mas que permanece aberta quanto ao sentido (com o terceiro gostar empregado intransitivamente), numa mescla de acabamento e inacabamento que volta a ecoar nove versos depois, na frase de Santo Agostinho: Nondum amabam et amare amabam. Como o amare amabam, tão recorrente na tópica poética depois de Agostinho, o gostar "de" não é um gostar de algo, mas um gostar intransitivo, autorreferente e infinito: um gostar de gostar (de gostar...).

A hipótese, então, está lançada: a leitura do poema, o desvendamento de seu núcleo, pode ser mais bem sustentada supondo-se que a solução da sentença enigmática sobre o destino da metafísica entre Kant e Hegel está cifrada no primeiro verso. Antes de tentar comprovar essa interpretação se faz necessário, no entanto, examinar o poema como um todo:

3 Optou-se por manter a ortografia original nas transcrições dos documentos do espólio pessoano. Agradecemos Biblioteca Nacional de Portugal por nos facultar os textos do espólio de Fernando Pessoa. [BNP/E3-69-54]. 
Gostava de gostar de gostar.

Um momento... Dá-me de ali um cigarro,

Do maço em cima da mesa-de-cabeceira.

Continua... Dizias

Que no desenvolvimento da metaphysica

De Kant a Hegel

Alguma coisa se perdeu.

Concordo em absoluto.

Estive realmente a ouvir.

Nondum amabam et amare amabam (Santo Agostinho).

Que coisa curiosa estas associações de idéas!

Estou fatigado de estar pensando em sentir outra coisa.

Obrigado. Deixa-me acender. Continua. $\mathrm{Hegel}^{4} \ldots$

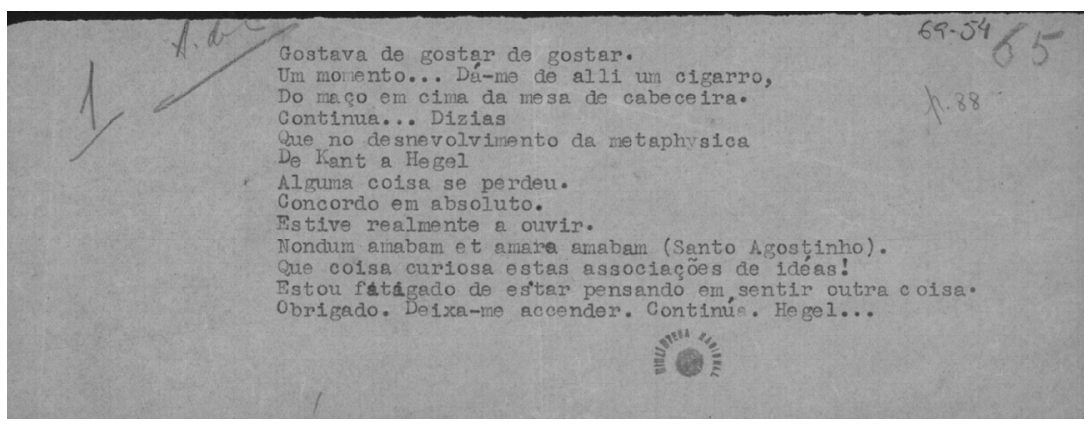

O poema está montado como pequena cena dramática, como um breve "drama estático 5" na acepção que lhe dá Fernando Pessoa. O diálogo transcorre na intimidade de um quarto (como Tabacaria, mas sem o mundo exterior), tendo por personagens o eu lírico e um interlocutor, muito embora seja cabível imaginar que também se trate de uma conversa do sujeito consigo mesmo, de um só eu dividido entre o próprio eu e um tu. O diálogo que ocorre "objetivamente" é entrecortado por outro, que se passa no interior do sujeito lírico (haveria, nesse caso, um monólogo interior sobreposto ao diálogo intersubjetivo): é este quem escreve (ou pensa) que "gostava de gostar de gostar" e diz "um momento", interrompendo a fala de seu interlocutor para pedir que lhe passe o cigarro do maço em cima da mesa de cabeceira. Um

4 [BNP/E3-69-54].

5 O termo "drama estático" é utilizado por Álvaro de Campos num poema que contém as seguintes indicações nas primeiras linhas: A Fernando Pessoa depois de ler o seu drama statico "O Marinheiro" em "Orpheu I" -Fernando Pessoa, O Marinheiro, (Lisboa: Ática, 2011), 59. No poema com data de 1918, Álvaro de Campos faz referência à peça de teatro, O Marinheiro, publicada por Fernando Pessoa em Março de 1915 na revista Orpheu. 
momento: a pausa para o cigarro é necessária para que o eu considere o nexo daquilo que pensou ("Gostava de gostar...") e aquilo que estava sendo dito, mas que afinal o leitor do poema não saberá o que foi.

Com domínio impecável da temporalidade lírico-dramática, que lembra mais uma vez Tabacaria, Pessoa-Álvaro de Campos lança o leitor de chofre no verso inicial da pequena cena dramática, verso inicial este que é talvez na verdade algo dito mentalmente pelo eu poético, que se liga, entretanto, por associação de ideias ao discurso anteriormente pronunciado por aquele com quem confabula. Se for assim, a frase inicial do poema não constitui exatamente o início dele: o drama já havia começado antes da encenação propriamente dita. Usando a distinção aristotélica, pode-se dizer que o nó da trama já está dado antes da ação ${ }^{6}$. É como se a cortina do teatro - também um theatrum mentis - se abrisse no momento em que o ator diz a primeira frase. A cena que se presencia é, portanto, continuação do diálogo já entabulado antes, que o engenheiro interrompe com o pedido de cigarro, mas ato contínuo insta para que o outro prossiga: "Continua..." O interlocutor, porém, não tem propriamente voz alguma: pelo contrário, é pela voz poética que se sabe de sua afirmação sobre algo que foi perdido no desenvolvimento da metafísica de Kant a Hegel. Concordando com essa afirmativa, o eu poético diz que esteve realmente a ouvir, embora, verso seguinte, a frase agostianiana também lhe venha à mente: Nondum amabam et amare amabam.

Em seguida, o narrador exprime (para si somente e para o leitor?) seu espanto com a curiosa associação de ideias, e a constatação é seguida da declaração de sua fadiga "Estou fatigado de estar pensando em sentir outra coisa", em frase que também se compõe de três segmentos "Estou fatigado" - "de estar pensando" - "em sentir outra coisa", cujo ritmo, portanto, é bastante semelhante ao "gostava de gostar de gostar" e ao dito agostiniano. Os "conteúdos", no entanto, são distintos, pois, diferentemente destes, que acabam na intrasitividade do verbo amar e do gostar pelo gostar, o sentir aqui é transitivo, referindo-se a outra coisa; enquanto o gostar se basta a si mesmo, é um "gostar de gostar", o sentir cansa, porque, preso ao pensar, é um prazer que depende de algo outro.

Vem o agradecimento pelo cigarro recebido e a solicitação de que o interlocutor espere um pouco para que ele o acenda. E a interpelação para que ele continue seu raciocínio: então dizias que Hegel...

O poema se parece com uma sequência, um contínuo de interrupções. Tudo é separado e tudo é uno no universo, lembra a teoria do drama estático. Há nesses poucos treze versos um elo e um hiato entre três períodos no tem-

${ }^{6}$ Aristóteles, Poética, trad. de Eudoro de Sousa (Lisboa: INCM, 2008), 1455a: "o nó é constituído por todos os casos que estão fora da ação e muitas vezes por alguns que estão dentro da ação". 
po: um passado bem mais longínquo, atualizado pela citação de Agostinho, um passado mais próximo (época da metafísica alemã) e o presente (momento do diálogo). Abre-se, curiosamente, uma descontinuidade entre o presente e passado mais próximo, período em que algo se perdeu (pretérito perfeito), contígua à continuidade entre o passado mais distante (Agostinho) e o dia de hoje, que é dada pelos tempos verbais (pretérito imperfeito, imperativo, infinitivo, presente), assim como pela sonoridade, pelo paralelismo, no ritmo de versos baseados em verbos de sentido próximo.

$* * *$

Uma leitura possível do poema poderia dizer que o cansaço do sentir-pensar, característico do fastio existencial do engenheiro metafísico, resulta do discurso intelectual do interlocutor (que no limite pode ser ele mesmo): um assunto tão sério (e aborrecido: a metafísica alemã) leva o poeta a divagar, a entrecortar a fala do outro, embora por delicadeza diga que esteve "realmente a ouvir". No fundo, porém, ele está "pensando em sentir outra coisa", o que induz o leitor a imaginar que esta outra coisa se refere não àquela "alguma coisa" que se perdeu (e que teria então a ver com o enfado), mas com conteúdo da frase de Agostinho. (Como se pretende mostrar, essas duas coisas estão ligadas).

Ora, é sabido que o Nondum amabam et amare amabam se refere à concupiscência que o jovem Agostinho já sentia antes mesmo de senti-la, quando gostava dos prazeres carnais antes mesmo de tê-los experimentado, isto é, antes de conhecê-los efetivamente; daí o verbo intransitivo, que tem como objeto o próprio amar. Uma leitura assim reforçaria a interpretação que vê no desassossego pessoano uma herança da tradição agostiniana a respeito da inquietação humana (com seu refrão inquietum est cor nostrum). Mas o interesse da aproximação está noutro lugar: já pela construção e pela sonoridade, o "gostava de gostar de gostar" tem um vínculo formal mais estreito com a doutrina pessoana do sensacionismo, que não por acaso é explicada também segundo uma divisão ternária. Com efeito, conforme explicam alguns textos, o sensacionismo se fundaria: (1) numa sensação como tal ("todo objeto é uma sensação nossa"); (2) na consciência da sensação, consciência que dá o valor estético à sensação ("Toda arte é a conversão d'uma sensação em objeto"); e (3) numa elevação da consciência à segunda potência, como "consciência da consciência da sensação", donde resultaria "uma intelectualização de uma intelectualização, isto é, o poder de expressão". O resultado é a transformação de uma sensação imediata numa sensação "refletida" ("Portanto, toda a arte é a conversão d'uma sensação numa outra sensação" "). Assentado

7 Fernando Pessoa, Sensacionismo e outros ismos (Lisboa: INCM, 2009), 178. 
nesses três degraus, nessa consciência da sensação elevada à potência, o sensacionismo não é, ou não é apenas, uma doutrina filosófica ou um modo de pensar, visto que a intelectualização proposta como arte se destina sobretudo a aprimorar a capacidade expressiva. ${ }^{8}$

A capacidade de submeter a sensação a um processo de intelectualização visando a expressão poética lembra em muito a maneira pela qual o primeiro romantismo alemão procurou desenvolver as ideias de reflexão e exposição presentes em Kant e em Fichte. Radicada no juízo reflexionante kantiano, a doutrina-da-ciência mostra que, para alcançar a esfera transcendental, o filósofo precisa galgar um nível superior de consciência, que o eleve acima da consciência natural do senso comum, mas essa consciência à segunda potência se faz em paralelo ou em simultaneidade com a consciência natural ou à primeira potência. Toda a dificuldade do discurso filosófico reside em apresentar essas duas séries reflexivas em sua reciprocidade dialética, trabalho realizado, como bem mostrou Rubens Rodrigues Torres Filho, mediante a imaginação. O romantismo de Jena leva avante esse problema da exposição (Darstellung) simultânea das duas séries reflexionantes, a filosófica e a natural, concebendo-o como a tarefa artística e literária por excelência. Novalis explica que o processo de se alçar a um degrau mais alto de consciência é o ato pelo qual o eu comum se apropria de seu eu superior ou transcendental e mantém com ele uma relação de fecundidade mútua, pela qual se gera uma poesia ou filosofia genuinamente artística. Voltando um pouco mais a Kant, Friedrich Schlegel considera a clareza de consciência sobre os modos de operação do espírito a principal característica do discernimento crítico, que está ligada à compreensão de que todo texto ou locução, literária ou não, é atravessada pela ironia. Haveria, assim, uma primeira afinidade entre o romantismo alemão e Fernando Pessoa, já que, nos dois casos, a clareza de consciência (que Novalis chama de Besonnenheit) significa, ao mesmo tempo, instância crítica e força expressiva. Sobre a consciência da consciência na ironia, diz Bernardo Soares, "autor" do Livro do Desassossego:

O homem superior difere do homem inferior, e dos animais irmãos deste, pela simples qualidade da ironia. A ironia é o primeiro indício de que a consciência se tornou consciente ${ }^{9}$.

8 É o que torna a literatura e a arte diferentes de ciência e filosofia: "Perguntando qual o fim da arte, o sensacionismo constata que elle não pode ser a organisação das sensações vindas do exterior, porque esse é o fim da sciencia; nem a organisação das sensações vindas do interior, porque esse é o fim da filosofia; mas sim, portanto, a organisação das sensacões vindas do abstracto. A arte é uma tentativa de crear uma realidade inteiramente differente d'aquella que as sensações apparentemente do exterior, e as sensações apparentemente do interior nos suggerem." (Pessoa, Sensacionismo, 171-172).

9 Fernando Pessoa, Livro do Desasocego. (Lisboa INCM, 2010), 341. Os textos 
A proximidade do primeiro romantismo alemão com a concepção poética mais geral do sensacionismo ainda pode parecer superficial, e não permite, naturalmente, desvendar a charada contida no poema de Álvaro de Campos: o que se perdeu na metafísica entre Kant e Hegel é um segredo bem guardado, que a perfeita iconicidade do poema se recusa a revelar, e que só uma investida na arca pessoana poderá ajudar a desvendar.

Como quer que seja, qualquer comparação entre Fernando Pessoa e o romantismo teria de passar mesmo pela consciência da consciência. De fato, já desde seus primeiros escritos se pode observar a proximidade do poeta português com aquilo que Fichte designa por "reflexão". Enquanto para o autor da doutrina-da-ciência o sujeito filosofante deve ser aquele que sente, pensa, age e, ao mesmo tempo, tem consciência de seus sentimentos, pensamentos e ações, para o Interseccionismo pessoano "[...] o grau mais alto da actividade complexa do espírito é quando estamos ao mesmo tempo prestando attenção a um objecto exterior e a uma corrente de sensações ou pensamentos". Intersecção na arte significaria simultaneidade do sentir e do refletir, a capacidade do sujeito de perceber o que o afeta exteriormente, observando o que se passa em si mesmo. (Ocioso lembrar que este é um problema incontornável da epistemologia moderna, que desde Galileu, Descartes e Locke se vê às voltas com a diferença entre as qualidades primárias "objetivas" e as qualidades secundárias "subjetivas", entre aquilo que é a coisa mesma e aquilo que o sujeito percebe a seu respeito.) Acontece que, se é bem entendida, a coexistência do sentir e do pensar pode significar também uma reflexão sobre o sentimento, uma maneira de se afastar de si, afastamento que se traduz na forma irônica e distanciada pela qual o criador lúcido e ponderado se distancia de suas emoções imediatas, podendo com isso abdicar de sua individualidade empírica para se desdobrar em diferentes personalidades ou personas literárias. Antes de qualquer outra coisa, o poeta deve se posicionar como observador da própria emoção, transformando-se no primeiro crítico de si mesmo. Longe de todo sentimentalismo, essa fusão da figura do escritor e da figura do crítico é uma das perspectivas mais importantes que o romantismo alemão abriu para a modernidade.

A crítica, no entanto, é apenas uma das atividades conscientes, apenas uma das modalidades de existência do fazedor-fingidor, pois outras convi-

\footnotetext{
pertencentes ao projeto do Livro do Desassossego podem ser divididos em três fases: na primeira os textos são assinados por Fernando Pessoa, na segunda fase Vicente Guedes, personalidade literária pessoana, assina os textos destinados a este projeto e na terceira fase, a partir de 1929, o semi-heterônimo Bernardo Soares assume o encargo do projeto do desassossego.
} 
vem com ele no sujeito filosófico ou poético. O Eu é múltiplo, uma comunidade de indivíduos (gênio é um plural interior, como se lê numa das muitas formulações de Novalis), o que certamente antecipa a concepção heteronímica de Fernando Pessoa. O valor da lucidez filosófico-poética reside justamente em permitir uma postura altamente desconfiada diante da suposta evidência de que a emoção tem a primazia na busca de expressão, e de que a personalidade é um dado inquestionável. Se isso é correto, a aproximação com a obra de Pessoa traz já a vantagem de ajudar a corrigir algo da visão deturpada que se tem do idealismo fichtiano e o romantismo de Jena, duas maneiras de pensar que enfatizaram bastante a importância da intersubjetividade, cuja recepção, no entanto, continua a se ressentir do lugar-comum segundo o qual seriam filosofias subjetivistas. Sem que seja necessário fazer um trabalho historiográfico mais detido sobre as fontes por ele utilizadas - o que sem dúvida seria desejável -, é possível afirmar que o projeto poético de Fernando Pessoa ajuda a recuperar um dos aspectos mais originais da filosofia romântica, o desdobramento do eu em diversas figuras da consciência que devem se concretizar em personas literárias ou artísticas consistentes, consoante com o princípio de que o redobro da consciência é o único veículo capaz de dar expressão poética e espiritual às descobertas mais radicais do pensamento filosófico. Ou seja, Fernando Pessoa consegue resgatar indiretamente uma iniciativa que Hegel não mediu forças em combater, pois o autor da Fenomenologia do espírito procurou apresentar o romantismo como uma figura da consciência subjetiva infeliz, e a ironia como resultado do impasse em que se encontrava o subjetivismo idealista de Kant e Fichte. Essa visão, felizmente, já não é mais preponderante. Entretanto, ela certamente dominava à época em que Álvaro de Campos redige o seu poema. Para uma história das ideias quase hegemônica, baseada sobretudo na visão hegeliana da história da filosofia, a dialética seria o ponto de chegada do Idealismo Alemão, o término de um percurso que fora iniciado por Kant; a filosofia do espírito absoluto teria posto fim ao idealismo subjetivo kantiano-fichtiano, e aberto caminho para o verdadeiro sistema da filosofia. Ainda sem que se saiba por que caminhos, Fernando Pessoa parece ter intuído que algo estava errado nesse modo como a história era contada.

O "homem completo é um pequeno povo", diz Novalis: a pluralidade do Eu no romantismo é uma forma de politeísmo interno, e o indivíduo nada é sem a alteridade, sem a intersubjetividade. Diferentemente do que o apresenta Hegel, o primeiro romantismo alemão ou romantismo de Jena se concebe como uma maneira coletiva de fazer filosofia e poesia ("filosofar em conjunto", "poetizar em conjunto" são os seus lemas), que antecipa o empenho de ressuscitar o paganismo em Fernando Pessoa, como projeto de criação coletivo entre os diferentes heterônimos, cujo centro, mentor ou mestre é Alberto Caeiro. Todo homem precisa ser um celebrador da vida e da poesia, 
e se a época é estéril em produzir artistas, porque não proporcionar uma multiplicação artificial de seres criativos a partir da própria singularidade individual? Por que um poeta não pode - um pouco contra tudo e todos - assumir a missão de criar sozinho toda uma mitologia coletiva? Alberto Caeiro, Ricardo Reis, Álvaro de Campos, Bernardo Soares etc. não ganharam vida própria nessa constelação que é a mitologia heteronímica? Em um texto do espólio intitulado Aspetos, Pessoa afirma seu anseio de ser um criador de mitos: "Desejo ser um criador de mythos, que é o mysterio mais alto que pode obrar alguem da humanidade ${ }^{10 "}$.

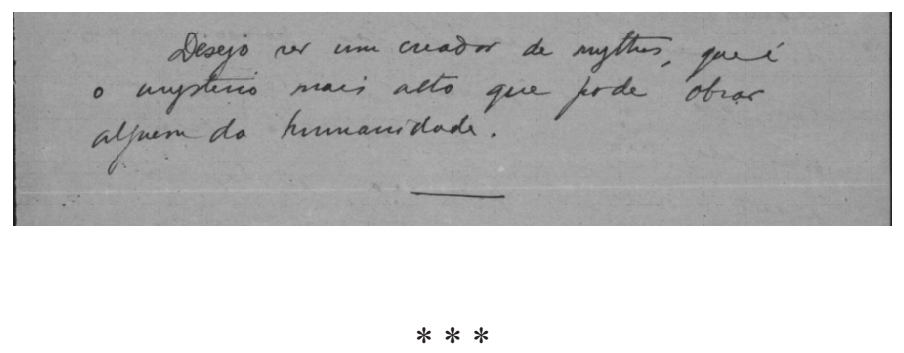

Para Novalis, o ato verdadeiramente primeiro ocorre quando o eu empírico se apropria de um Eu superior, quando ele desperta em si uma "personalidade estranha", "estrangeira", uma figura aérea, "alheia". Ainda aqui não se poderia dizer que houve influência direta do autor dos Discípulos de Sais em Fernando Pessoa, que já estava à procura de um "estilo alheio", de um "falar alheio" ou "escrever em alheio" antes de conhecer os textos do poeta e filósofo romântico. Mas o contato com a obra de Novalis vem por certo confirmar e acentuar esse traço que já havia despontado no poeta português. Um pouco como em Kant, que despertou do seu sono dogmático lendo Hume, também Pessoa parece ter descoberto em Novalis a fórmula terapêutica para despertar os homens de seu torpor, de um torpor que pode não ser apenas individual, mas coletivo, um torpor nacional. O seu texto Provincianismo Português, de 1928, faz referência explícita a essa terapêutica novalisiana:

Para o provincianismo há só uma terapêutica: é o saber que ele existe. O provincianismo vive da inconsciência; de nos supormos civilizados quando não o somos, de nos supormos civilizados precisamente pelas qualidades que o não somos. O princípio da cura está na consciência da doença, o da verdade no conhecimento do erro. Quando um doido sabe que está doido, já não é doido. Estamos perto de acordar, disse Novalis, quando sonhamos que sonhamos ${ }^{11}$.

10 [BNP/E3-20-73]

11 Fernando Pessoa, Crítica - Ensaios, Artigos e Entrevistas (Lisboa: Assírio \& 
A tomada de consciência de uma enfermidade (o provincianismo, a inconsciência, a loucura) já é uma maneira de se livrar dela, já é o "princípio da cura". Com um pouco de ouvido, o leitor se dá conta da similitude: entremeada pelo "disse Novalis", a frase final de Provincianismo português se escande nos três mesmos tempos marcantes do poema de Álvaro de Campos: Estamos perto de acordar - quando sonhamos - que sonhamos.

Comparando os dois textos, não há como resistir à tentação de ler o poema do engenheiro Álvaro de Campos pensando que a chave de seu enigma estaria de algum modo codificada apenas no plano rítmico e sonoro, já que em momento algum os versos dizem explicitamente o que foi que se perdeu na história da metafísica de Kant a Hegel. Noutras palavras, a simetria da sentença de Novalis com o "Gostava de gostar de gostar" e com o amabam et amare amabam talvez seja um indício a ser explorado para se encontrar finalmente aquele algo que, segundo o poema, teria se perdido.

A conjectura ganha força quando se lê a versão em francês do fragmento novalisiano. Fernando Pessoa conhecia os escritos de Friedrich von Hardenberg pela seleção que Maurice Maeterlinck publicou em Paris e Bruxelas pela editora Paul Lacomblez em 1914. Com prefácio e tradução do dramaturgo, poeta e ensaísta belga, a obra tinha por título Les disciples à Sais et Les fragments. O fragmento 16 das Observações Entremescladas foi assim vertido por Maeterlinck:

Nous sommes près du réveil quando nous rêvons que nous rêvons. ${ }^{12}$

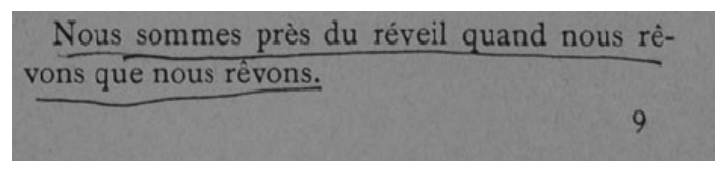

No exemplar que lhe pertenceu, e que se encontra na Casa Fernando Pessoa, em Lisboa, o poeta português sublinhou esta frase, assim como várias outras passagens da tradução ${ }^{13}$. Bem mais do que estas, no entanto, o

\footnotetext{
Alvim, 2000), 373.

12 Friedrich von Hardenberg Novalis, Les disciples à Sais et Les fragments. (Bruxelles: Paul Lacomblez, 1914), 77.

13 É importante ressaltar que Pessoa não somente leu, sublinhou, e aproveitou em seus escritos a leitura do livro de Novalis em questão, mas também pensou em traduzi-lo, como se pode comprovar na seguinte lista pertencente ao espólio pessoano:

"200 ou 250 reis

Anton Tchecov: Vania

? - José Enrique Rodó: Ariel

? - J. M. Robertson: Short History of Ch (?)

Novalis: Discipulos em Saïs, Fragmentos.
} 
fragmento 16 desperta um interesse distinto por força do ritmo ternário e pela reiteração sonora: réveil, rêvons, rêvons. Essa aliteração abre uma possibilidade de sentido inesperada, já que o re de réveil é preciosidade do francês (a palavra vem do latim evigilare, que dá o português vigília), preciosidade esta que permite uma aproximação rítmico-fonética dos termos semanticamente opostos réveil e rêver (despertar e sonhar), que provavelmente não se encontra em nenhuma outra língua. ${ }^{14}$ Afinal, seria esta a chave do enigma - a identificação do sentir e do refletir, do sonhar e do estar acordado?

$$
* * *
$$

A mistura de vida e sonho conhece todo um colorido na pena dos diferentes heterônimos e semi-heterônimos da galáxia pessoana. Em alguns trechos do Livro do Desassossego, por exemplo, a ênfase está na fusão de sonho e consciência:

Estou quasi convencido de que nunca estou disperto. Não sei se não sonho quando vivo, se não vivo quando sonho, ou se o sonho e a vida não são em mim coisas mixtas, interseccionadas, de que meu ser consciente se forme por interpenetração. ${ }^{15}$

Tenho sido sempre um sonhador irônico, infiel às promessas interiores. Gosei sempre, como outro e estrangeiro, as derrotas dos meus devaneios, assistente casual ao que pensei ser. ${ }^{16}$

Kant: Critica da razão pura.

Lord Dunsany: (Dramas)

? G. K. Chesterton: Herejes

? G. B. Shaw: Homem e Superhomem

Francisco Sanches: Quod nihil scitur. :Antologia portuguesa (? vols)

Fernando Lopes: Historia da Philosophia

Antonio Mora: Prolegomenos, etc..."

Outro fato interessante deste documento é a presença de Kant, de quem Pessoa também foi leitor e pensou em traduzir parte da obra. [BNP/E3-14/3-75].

14 Rêver, por sua vez, é de etimologia incerta. Sua origem mais plausível é o verbo dinamarquês roeuve, que significa errar, vagabundear, de onde vem ainda to rove, delirar, em inglês. No texto original em alemão, a sugestão poética parece bem remota. Ele diz: "Wir sind dem Aufwachen nah, wenn wir träumen, dass wir träumen." Na tradução brasileira de Rubens Rodrigues Torres Filho, o fragmento 16 das Vermischte Bemerkungen é assim traduzido: "Estamos próximos do despertar quando sonhamos que sonhamos". (Friedrich von Hardenberg Novalis, Pólen - Fragmentos, diálogo, monólogo, trad. Rubens Rodrigues Torres Filho (São Paulo: Editora Iluminuras, 2009), 43.

$15[\mathrm{BNP} / \mathrm{E} 3-4-23]$

$16[\mathrm{BNP} / \mathrm{E} 3-4-13]$ 
Nunca durmo: vivo e sonho, ou antes, sonho em vida e a dormir, que também é vida. Não há interrupção em minha consciência: sinto o que me cerca se não durmo ainda, ou se não durmo bem; entro logo a sonhar desde que deveras durmo. Assim, o que sou é um perpetuo desenrolamento de imagens, conexas ou desconexas, fingindo sempre de exteriores, umas postas entre os homens e a luz, se estou disperto, outras postas entre os fantasmas e a sem-luz a que se vê, se estou dormindo. Verdadeiramente, não sei como distinguir uma coisa da outra, nem ouso afirmar se não durmo quando estou disperto, se não estou a dispertar quando durmo. ${ }^{17}$

A fusão, a interpenetração entre sonhar e estar acordado descrita pelo guarda-livros Bernardo Soares em documentos que pertencem à última fase do projeto do Livro do Desassossego também já aparecia de algum modo na concepção do interseccionismo:

I may add that the term "intersectionist" applied to the poems is not the distinction of a school or current, like "futurist" or "imagist", but a mere definition of process, for in those poems it has been my intention to register, in intersection, the mental simultaneity of an objective and of a subjective image, such as the room a man is day-dreaming in and the images his day-dream consists of. ${ }^{18}$

Havendo simultaneidade entre a imagem objetiva e a subjetiva, o quarto no qual se encontra o sonhador do sonho diurno não se distingue das imagens que compõem o próprio day-dream, e assim também as pinturas que se veem no Livro do Desassossego, embora dotadas de uma temporalidade (as mudanças de cor do céu no decorrer das horas, por exemplo), parecem antes instantâneos de fenômenos concomitantes, ou a tentativa de captá-los como tais. Por outro lado, por mais que se lhes assemelhem, as divagações diurnas e vigílias noturnas de Bernardo Soares divergem daquilo que é descrito como próprio ao sensacionismo de Álvaro de Campos. A diferença entre sensacionismo e intersecionismo é assim assinalada:

Sensacionismo puro

A[lvaro] de [Campos] segue com uma grande intensidade e concentração de attenção a marcha do seu espirito (contrario do int[erssecion]mo) de modo que não há simultaneo nele mas sucessivo rapido.

Como as sensações estão sempre "em marcha", dá o dynamismo. - Preoccupa-se n'uma expressao das sensacões ${ }^{19}$.

17 [BNP/E3-3-72]

18 Pessoa, Sensacionismo, 387.

19 Pessoa, Sensacionismo, 150. É interessante ressaltar que o sensacionismo - movimento estético elaborado por Pessoa - estava relacionado com o romantismo, como fica comprovado no seguinte documento do espólio: 
No sensacionismo puro, não há um "simultanisar as sensações", mas a experiência de quebrar a associação de ideias, numa concentração e atenção do espírito sobre si mesmo que mais uma vez lembra o sentido da "reflexão" no idealismo e romantismo alemão. Para fazer uso da distinção lessingiana, pode-se dizer que o interseccionista se preocupa antes com o espaço, é mais visual, enquanto que o sensacionista persegue mais as sensações no tempo, ele é um escritor principalmente temporal. O diálogo entre o eu lírico e seu suposto interlocutor no poema de Álvaro de Campos narra justamente uma sequência entrecortada, um entrecruzamento no tempo de ideias díspares, mas de algum modo ligadas - a história da metafísica, a inquietude agostiniana (e também, agora, o fragmento novalisiano?) -, assim como a divisão entre a Tabacaria e a mansarda no seu famoso poema implica um seccionamento, uma observação reflexiva sobre a disparidade entre a ânsia interior e a sorridente tranquilidade externa, com a consequente busca de expressão para ela ("À Tabacaria do outro lado da rua, como coisa real por fora,/ E à sensação de que tudo é sonho, como coisa real por dentro.")

O tema também aparece em Ricardo Reis, em versos que glosam a tríplice presença do mesmo verbo. O poema, que está encimado pela palavra "Nirvana", diz na sua quadra inicial:

Vou dormir, dormir, dormir,

Vou dormir $\mathrm{sem}^{20}$ despertar,

Mas não dormir sem sentir

Que stou dormindo a sonhar. ${ }^{21}$

A repetição do verbo no primeiro verso da quadra imita um mantra, embora mais uma vez o dormir seja acompanhado de um sentir, de uma consciência que não é exatamente a da razão vigilante, mas ainda assim consciente de seu estado. Noutro poema escrito no dia seguinte ao deste, Ricardo Reis também sugere uma interessante explicação para o uso pessoano do verbo no intransitivo, sobre o qual valeria meditar:

\footnotetext{
O Sensacionismo é:

1. Um subjetivismo, como o romantismo.

2.

Os três elementos do sensacionismo:

1. O que começou com Walt Whitman: $\square$

2. O que começou com os simbolistas:

3. O que começou no cubismo e no futurismo: [BNP/E3-88-37]

20 Vou dormir sem despertar, no documento original-

21 [BNP/E3-51-62r].
} 
Dois é o prazer: gozar e gozá-lo.

Ao néscio elege o parvo, o sábio ao outro.

E o igual fado é diverso.

$\mathrm{Na}$ taça que ergo, ondeio, e vejo, as bolhas

Incluo no que sinto, e ao pegar

Mais puro stá na taça. ${ }^{22}$

O prazer tem duas acepções, a fruição de uma coisa e a fruição da própria ação de fruir. Um pouco como no estoicismo antigo, o que importa não é tanto acertar o alvo, não é ganhar o jogo, mas jogar bem, o que aqui supõe uma concepção da vida como exercício poético, pela qual a busca da poesia se torna mais importante que o poema acabado. $\mathrm{O}$ verbo intransitivo se inflecte, se volta para si mesmo, para que a palavra seja sentida em todo o seu sentido, num jogo autorreferente que espelha a condição reflexionante, a consciência que o poeta tem de seu próprio labor artístico.

$$
* * *
$$

Voltando ao sonho, Novalis também manifesta um forte desejo de identificação da vida onírica com a vida real:

Notre vie n'est pas un songe, mais peut-être en deviendra-t-elle un. ${ }^{23}$

\section{Notre vie n'est pas un songe, mais peut-être} en deviendra-t-elle un.

Esse fragmento da seleção de Maeterlinck também foi grifado por Fernando Pessoa em seu exemplar. A coletânea traz ainda outro fragmento contendo uma ideia correlacionada, que merece destaque: Le songe nous montre d'une manière remarquable la facilité qu'a notre âme à pénétrer dans tout objet, à se changer immédiatement en cet objet ${ }^{24}$.

A interpenetração do sujeito e do objeto é apresentada de maneira mais evidente no sonho, pois nele se percebe melhor como a alma se converte naquilo que ela mesma cria, como o mundo exterior é produzido na própria intimidade do sujeito: "Sonhamos com viagens através do todo cósmico -

22 [BNP/E3-51-62v].

23 Novalis, Les disciples, 78: "Nossa vida não é um sonho, mas talvez deva se tornar um."

24 Novalis, Les disciples, 78: "O sonho nos mostra de maneira notável a facilidade que a alma tem de penetrar em qualquer objeto, de se transformar imediatamente nesse objeto". 
Então o universo não está dentro de nós?" 25 Parafraseando Pessoa, as coisas se fingem de externas, quando na verdade sua significação e produção depende daquele que as percebe. Do mesmo modo que a criação poética, o sonho é como que a solução para o problema do conhecimento do mundo objetivo, já que, se bem compreendido, ele mostra como aquilo que aparece como exterior na vigília é também - como ensina o idealismo kantiano e fichtiano uma construção interna, que está subordinada às faculdades transcendentais para a sua produção.

Sonhar é sonhar que se sonha, sentir que se sente, um sentir consciente, uma forma de compreensão de si, uma maneira de ser consciente não distinta para Novalis daquela que ocorre na reflexão filosófica, onde a consciência artificial do filósofo busca dar conta da produção inconsciente do mundo objetivo pela consciência natural. Novalis transfere, portanto, para dentro do universo onírico aquilo que era o mais próprio da reflexão transcendental.

Talvez o melhor comentário sobre o tema do sonho em Novalis seja o de Rubens Rodrigues Torres Filho, que mostra, a partir da leitura de um dos Fragmentos logológicos, como sua escrita fragmentária foi capaz de transformar um texto ainda iluminista, racionalista, analítico do filósofo holandês Frans Hemsterhuis num resumo bastante sintético no qual se poderia reconhecer um processo de "onirização", já que, para proceder a essa transformação, o escritor teria nele empregado conscientemente a condensação e o deslocamento próprios do mecanismo do sonho segundo Sigmund Freud. ${ }^{26}$ É ainda Rubens Rodrigues Torres Filho quem melhor explica a duplicação do sujeito no sonho, como aquele que cria e aquele que assiste ao processo de criação. Comparando a conquista do transcendental por Kant com a descoberta do inconsciente por Freud, ele escreve: "[...] também o sonho não distingue o 'achar' do 'inventar', nele nos julgamos meros espectadores, ou mesmo participantes, daquilo que estamos criando. E, enfim, quem tem certeza de estar acordado?". 27

Como na reflexão da reflexão fichtiana e romântica, o eu que sonha, age e sente, ao mesmo tempo em que assiste, como seu observador, a seu agir e sentir. O sonho também é o lugar dessa potenciação reflexiva, como escreve Novalis, ao equiparar sonho e pensamento: "Pensar, no sentido comum, é

25 Novalis, Pólen, trad. Rubens Rodrigues Torres Filho, 43-45. Observações Entremescladas 17.

26 Rubens Rodrigues Torres Filho, "Novalis: O romantismo estudioso". (Novalis, Pólen, 18-19).

27 Rubens Rodrigues Torres Filho.. Novos ensaios de filosofia ilustrada, (São Paulo: Iluminuras, 2004), 47. 
pensar do pensar, comparar etc. dos pensamentos especificamente diferentes. Sonhar direto - sonhar refletido - sonhar potenciado ${ }^{28}$."

A capacidade que o processo onírico tem de se converter naquilo que produz é análoga à capacidade do eu que sonha de se multiplicar e produzir personas com que entra em diálogo. No sonho, ao contrário do que pensavam os antigos, o indivíduo não vive isolado, mas em companhia, pois cria um convívio para si. Talvez o primeiro a observar isso foi Addison, que faz notar na edição número 487 do Spectator (18 de setembro de 1712) o "maravilhoso poder" de que a alma dispõe no sonho, de saber criar companhia para si mediante "inúmeros seres de sua criação". Nas incontáveis cenas que fabrica, a alma é ao mesmo tempo "o teatro, os atores e espectador". Mais do que isso: no trabalho do sonho, a mente realiza a mais difícil das tarefas, a invenção. Pois nele a agilidade da alma é tal, que qualquer um é capaz de ler um jornal, um livro ou uma carta, que ele mesmo redigiu como se tivesse sido escrita por um outro. ${ }^{29}$

Para Novalis, a conversão da vida em sonho também significa a passagem de uma vida menos completa a uma vida mais plena e consciente de si, em que o eu individual convive com outros eus numa comunidade de espírito que é a verdadeira produtora do mundo (o tão incompreendido Eu fichtiano devendo ser constituído como um Eu supra-individual, único capaz de suplantar progressivamente a resistência do não-eu). Para Fernando Pessoa, a multiplicação heteronímica também é uma forma de vencer a passividade, a poesia coletiva de seus heterônimos lhe apareceu como a única maneira de superar a resistência espiritual de um meio hostil. Os sonhos de uma vida criadora são sonhos que, como a poesia, devem ser partilhados com os outros, pois são também sonhos sonhados por outros, como se lê no seu primeiro soneto em inglês:

We are our dreams of ourselves, souls by gleams,

And each to each other dreams of others' dreams. ${ }^{30}$

A poesia é uma forma de inspiração, de invenção, de vida onírica socializada, sonhos e versos "transmigram" de uma alma a outra, produzindo um

28 "Denken im gewöhnlichen Sinn ist Denken des Denkens, Vergleichen usw. der spezifisch verschiednen Gedanken. Direktes Träumen - reflektiertes Träumen - potenziertes Träumen." In: Friedrich von Hardenberg Novalis, Schriften. Das philosophische Werk, II, (Stuttgart: Kohlhammer, 1983), 63.

29 O insight addisoniano sobre o caráter inventivo do sonho é comentado por Borges em seu texto sobre o pesadelo de Sete noites. (Jorge Luis Borges, Obras Completas, (Buenos Aires: emecé, 2011), vol. 3, p. 371.

30 Fernando Pessoa, Poemas Ingleses (Lisboa: Ática, 1974), 156. 
tecido ao mesmo tempo individual e coletivo. É assim que os versos de Pessoa também já haviam sido de certo modo "sonhados" por Walt Whitman, que escreve no primeiro poema de The Sleepers:

I dream in my dream all the dreams of the other dreamers.

And I become the other dreamers. ${ }^{31}$

\section{Referências bibliográficas}

Aristóteles. Poética. Tradução de Eudoro de Sousa. Lisboa: INCM, 2008.

Borges, Jorge Luis. Obras Completas. Edição crítica de Rolando Costa Picazo e Irma Zangara. Buenos Aires: emecé, 2011.

Novalis, Friedrich von Hardenberg. Les disciples à Sais et Les fragments. Traduits de l'allemand et précédés d'une introduction par Maurice Maeterlinck. Bruxelles : Paul Lacomblez, 1914.

Novalis, Friedrich von Hardenberg. Pólen - Fragmentos, diálogo, monólogo. Tradução, apresentação e notas Rubens Rodrigues Torres Filho. São Paulo: Editora Iluminuras, 2009.

Novalis, Friedrich von Hardenberg. Schriften. Das philosophische Werk, II. Organização de Richard Samuel, Stuttgart: Kohlhammer, 1983, 3a ed., vol. 3.

Pessoa, Fernando. Crítica - Ensaios, Artigos e Entrevistas. Edição de Fernando Cabral Martins. Lisboa: Assírio \& Alvim, 2000.

Pessoa, Fernando. Livro do Desasocego. Tomos I e II. Edição de Jerônimo Pizarro. Lisboa INCM, 2010.

Pessoa, Fernando. Livro do Desassossego / por Bernardo Soares. Recolha e transcrição dos textos Maria Aliete Galhoz, Teresa Sobral Cunha ; prefácio e organização Jacinto do Prado Coelho. Lisboa: Ática, 1982.

Pessoa, Fernando. Livro do Desassossego por Vicente Guedes e Bernardo Soares. Volume I e II. Organização e notas de Teresa Sobral Cunha. Lisboa: Editorial Presença, 1990.

Pessoa, Fernando. O Marinheiro. Edição de Cláudia Souza. Lisboa: Ática, 2011.

Pessoa, Fernando. Pessoa por Conhecer. Edição de Teresa Rita Lópes. Lisboa: Estampa, 1990.

Pessoa, Fernando. Poemas Ingleses. Edição de Jorge de Sena. Lisboa: Ática, 1974.

Pessoa, Fernando. Sensacionismo e outros ismos. Edição de Jerônimo Pizarro. Lisboa: INCM, 2009.

Ribeiro, Nuno. "Fernando Pessoa leitor de Novalis e o problema da heteronímia", Revista Scripta 16 (2012). Belo Horizonte, PUCMG, 56-68.

Ribeiro, Nuno. Fernando Pessoa, Philosophical Essays: A critical edition. New

31 Walt Whitman, The complete poems of Walt Whitman (Hertfordshire: Wordsworth, 2006), 316. 
York: Contra Mundum Press, 2012.

Torres Filho, Rubens Rodrigues. Novos ensaios de filosofia ilustrada. São Paulo: Iluminuras, 2004.

Schlegel, Friedrich. $O$ dialeto dos fragmentos. Tradução, apresentação e notas Márcio Suzuki. São Paulo: Editora Iluminuras, 1997.

Souza, Cláudia. "A Estética do Desassossego: Fernando Pessoa e o romantismo alemão", in: Literatura, Vazio e Danação, org. Osmar Oliva. 1ed. Montes Claros: Editora Unimontes, 2013, v. 01, p. 101-113.

Suzuki, Márcio. O gênio romântico - crítica e história na filosofia de Friedrich Schlegel. São Paulo: Editora Iluminuras, 1998.

Whitman, Walt. The complete poems of Walt Whitman. Hertfordshire: Wordsworth, 2006. 